\title{
Physician Office vs Retail Clinic: Patient Pref- erences in Care Seeking for Minor Illnesses
}

\author{
Arif Abmed, BDS, $P b D, M S P H^{1}$ \\ Jack E. Fincham, $P b D^{2}$ \\ 'Henry W. Bloch School of Business and \\ Public Administration, University of Mis- \\ souri-Kansas City, Kansas City, Missouri \\ ${ }^{2}$ School of Pharmacy, University of Mis- \\ souri-Kansas City, Kansas City, Missouri
}

Conflicts of interest: none reported

\section{CORRESPONDING AUTHOR}

Arif Ahmed, BDS, PhD, MSPH 308 Bloch School

University of Missouri-Kansas City 5100 Rockhill Rd

Kansas City, MO 64110

ahmedar@umkc.edu

\begin{abstract}
PURPOSE Retail clinics are a relatively new phenomenon in the United States, offering cheaper and convenient alternatives to physician offices for minor illness and wellness care. The objective of this study was to investigate the effects of cost of care and appointment wait time on care-seeking decisions at retail clinics or physician offices.
\end{abstract}

METHODS As part of a statewide random-digit-dial survey of households, adult residents of Georgia were interviewed to conduct a discrete choice experiment with 2 levels each of 4 attributes: price $(\$ 59 ; \$ 75)$, appointment wait time (same day; 1 day or longer), care setting-clinician combination (nurse practitioner in retail clinic; physician in private office), and acute illness (urinary tract infection [UTI]; influenza). The respondents indicated whether they would seek care under each of the 16 resulting choice scenarios. A cooperation rate of $33.1 \%$ yielded 493 completed telephone interviews.

RESULTS The respondents preferred to seek care for both conditions; were less likely to seek care for UTI ( $\beta=-0.149 ; P=.008)$; preferred to seek care from a physician $(\beta=1.067 ; P<.001)$ and receive same day care $(\beta=-2.789 ; P<.001)$. All else equal, cost savings of $\$ 31.42$ would be required for them to seek care at a retail clinic and $\$ 82.12$ to wait 1 day or more.

CONCLUSIONS Time and cost savings offered by retail clinics are attractive to patients, and they are likely to seek care there given sufficient cost savings. Appointment wait time is the most important factor in care-seeking decisions and should be considered carefully in setting appointment policies in primary care practices.

Ann Fam Med 2010;8:117-123. doi:10.1370/afm.1052.

\section{INTRODUCTION}

T 2005 there were approximately 1.2 billion ambulatory care visits in the United States-a 36\% increase in 10 years. ${ }^{1}$ One-half of these visits, representing 197 visits per 100 persons, were to primary care physicians in office-based practices. With older patients making more physician office visits, aging of the population has contributed to the increased volume $^{1,2}$ and is likely to further increase the demand for physician services. Although the likely impact of the increased demand on office visit attributes, such as time to appointment and waiting time, is unknown, delay of care is a persistent undesirable feature of the health care system. ${ }^{3}$ A niche market addressing these very attributes is rapidly developing in the United States. Recently there has been a phenomenal growth of walk-in clinics located in pharmacies, department stores, shopping malls, and even such unconventional locations as airports. ${ }^{4,5}$ Generally staffed with nurse practitioners or physician assistants, retail clinics (also known as convenient care clinics or store-based health clinics) offer treatment for common acute illnesses, screening tests, and vaccinations to patients aged 18 months or older. Most clinics have referral or consultative arrangements with local physicians or clinics. Cost, time savings, and convenience are promoted 
as the advantages of seeking care at these clinicspatients do not need appointments to see a clinician, are usually attended to in a matter of minutes, and can fill prescriptions at on-site pharmacies, if necessary.

Currently these clinics are located mostly in major metropolitan areas. With many big-box retailers and pharmacy chains, such as Walgreens, joining the fray, ${ }^{6-8}$ however, these clinics are likely to expand outside major metropolitan areas. As the coverage in mainstream media and business publications grows, retail industry analysts claim a significant increase in public awareness of in-store clinics. ${ }^{9}$ A recent national poll on children's health found that $10 \%$ of children have used a retail clinic, and $70 \%$ of the parents of children who have visited a retail clinic are likely or very likely to take them back. ${ }^{10}$ In a 2005 Wall Street Journal online poll, $41 \%$ of adults indicated that they were somewhat or very likely to use a retail clinic for basic medical services. ${ }^{11}$ Several major insurers have already started reimbursing for retail clinic services, ${ }^{12,13}$ and with the increasing emphasis on consumer responsibility, more insurers are likely to cover such services. ${ }^{6}$ As of early 2009, approximately three-quarters of all retail clinics accept insurance payment. ${ }^{14}$

Individual physicians and physician organizations, including the American Academy of Family Physicians, have expressed concerns about the impact of retail clinics on quality, continuity of care, and medical home. ${ }^{15-18}$ In some quarters, there is concern about increased prescription drug use because most retail clinics are located in pharmacies. ${ }^{19}$ Many of these concerns are also shared by the general public. ${ }^{11}$ Even so, some of these concerns are yet to be substantiated, as most clinics have maintained good relationships with local primary care physicians and adhere closely to evidence-based protocols. ${ }^{20}$ An analysis of patient records reported a very high rate of adherence to national clinical practice guidelines for acute pharyngitis by nurse practitioners and physician assistants in a retail clinic chain. ${ }^{21}$ Patient satisfaction is also very high among retail clinic users, and $89 \%$ of the children with retail clinic use have a usual source of care. ${ }^{10,11}$ Various federal and state regulatory bodies have identified these clinics as a potential avenue for expanding access to health care, and many see it as a viable option for the uninsured. ${ }^{22-24}$

It is too early to predict the overall impact of retail clinics on the US health care system and whether the scope of services in these clinics will remain the same. ${ }^{13}$ Even so, competition from retail clinics has prompted many physicians to make changes in their practices, including extending office hours to evenings and weekends and accommodating patients who do not have appointments. ${ }^{12}$ The key attributes of retail clinics — time and cost savings — are also major factors in this competition and transformation. Waiting time has been well documented to be negatively correlated with patient satisfaction with physician visits, and the association is stronger among those who are not elderly compared with the elderly. ${ }^{25-28}$ Similarly, appointment wait time is one of the strongest predictors of satisfaction with access to care. ${ }^{29,30}$ The relative importance of time and cost attributes may vary depending on the type of illness. Researchers in the United Kingdom have found that people are willing to trade between different factors in choosing the method for managing minor illnesses, and sufficient reduction in wait time and cost may make a less-preferred management method more attractive. ${ }^{31}$

Discrete choice experiments (DCEs) have been used successfully to evaluate consumers' decision making pertaining to valuation of health care services. ${ }^{32}$ DCEs have been shown to allow consumers to state preferences for choices when examining several options and to effectively estimate consumer utilities through willingness to pay for changes in the attribute. ${ }^{33-35}$

In this article we report findings from a DCE that investigated the likely effects of cost of care, type of condition for which care is sought, type of care setting, and appointment wait time on care-seeking decisions at retail clinics or physicians' offices.

\section{METHODS}

\section{Study Population and Sample}

The fall 2007 Georgia Poll was used to obtain the study sample of respondents. The Georgia Poll is a statewide random-digit-dial survey of Georgians aged 18 years and older routinely conducted at least 2 times a year by the Survey Research Center at the University of Georgia. The specific Georgia Poll questions and procedures are approved by the University of Georgia Institutional Review Board before conducting each study. The sampling design of the study called for conducting a total of 500 telephone interviews as a targeted number from a random-digit-dial sample of Georgia households. Actual random generation of the telephone numbers by computer was the result of a stratified sampling procedure with probabilities of selection proportional to listed residential telephone numbers in different parts of the defined sample universe, the State of Georgia. Within each area code and exchange (3-digit prefix), the desired number of households were called using randomly generated numbers that included both listed and unlisted telephone numbers. ${ }^{36}$ The result of this procedure insures an equal and known probability of selection of sample elements. The second component of this determina- 
tion was the selection of a respondent within the telephoned household. The person in the household older than 18 years and who celebrated the last household birthday was selected to participate in the survey. This method yielded 1,491 eligible respondents from 5,448 telephone numbers called. The cooperation rate was $33.1 \%$, resulting in a sample of 493 completed interviews. The cooperation rate was computed using the American Association for Public Opinion Research (AAPOR) guidelines for reporting results of surveys; the rate computed here is AAPOR cooperation rate 3 $(\mathrm{COOP} 3)=$ interviews $/$ (interviews + partials + refusals $)$. Approximately $25 \%$ of all interviews were monitored by a supervisor for quality control purposes. Any interviewer error resulted in elimination of the respondent from the sample.

\section{Study Design and Measures}

We undertook a full-factorial DCE that contained 16 questions included in the October 2007 Georgia Poll. The poll contained additional 50 questions that were not related to the research reported here. The resulting data were produced, along with a standard battery of demographic items (sex, education, income, age, marital status, home ownership, and urban/rural status).

We used 2 price levels $(\$ 59 ; \$ 75), 2$ levels of appointment wait time (same day; wait 1 day or more), 2 types of care setting-clinician combination (nurse practitioner at retail clinic; physician at private office), and 2 symptom scenarios of acute illnesses (urinary tract infection [UTI]; influenza) to set up 16 choice scenarios in a $2 \times 2 \times 2 \times 2$ factorial design. Each symptom scenario was included in the preamble statement to the respondents, who were then offered 8 scenarios (questions) comprising of all possible combinations of the levels of the other 3 attributes. Using a computer-aided telephone interview protocol, adult residents of Georgia were presented with 1 scenario at a time and asked whether they would seek care under each scenario. For example, in 1 of the 8 choice scenarios subsequent to each of the 2 preamble statements, the respondents were asked, "If you received care from a supermarket, discount store, or chain phar- macy with a nurse practitioner and had to wait 1 day or more for care at a price of $\$ 59$, would you use this option?" Table 1 displays details of the preamble text and the attributes.

At the time of the survey, treatment of influenza and UTI were among the most commonly available services at retail clinics. Price levels were determined by using the prevailing fee at a large retail clinic chain in Georgia and inflation-adjusting the median expenditure for a primary care physician's visit reported in the 2004 Medical Expenditure Panel Survey. ${ }^{37}$

\section{Statistical Analysis}

Random-effects logistic regression was used to quantify preferences for care at retail clinics and physicians' offices and the contribution of each attribute mentioned above in the preferences. The dependent variable in the logistic regression was the respondents' willingness to seek care under each choice scenario (yes/no). For comparative purposes, in the race variable, white was the reference group; for education, high school or less was the reference group; and for sex, male was the reference group. Willingness to pay for change in each nonprice attribute was indirectly estimated from the regression model as the ratio between the coefficient for the non-price attribute and the additive inverse of the coefficient for price. ${ }^{35}$ The random-effects logistic regression was facilitated
Table 1. Preamble Statement and Attributes Used in the Discrete Choice Experiment

\begin{tabular}{|c|c|}
\hline \\
\hline \multicolumn{2}{|c|}{$\begin{array}{l}\text { For the next set of items, I would like you to place yourself in the following situation [symptom } \\
\text { scenario]..., and you have decided to seek medical care. The type of care that you can receive } \\
\text { is either from a physician at a private practice OR from a nurse practitioner at a clinic within a } \\
\text { supermarket, discount store, or chain pharmacy. You could either obtain these services on the } \\
\text { same day or wait } 1 \text { day or more. The price you would pay would be either } \$ 59 \text { or } \$ 75 \text {. Now I } \\
\text { am going to read you hypothetical situations involving where you might receive care, whether } \\
\text { care was received on the same day or } 1 \text { day later, and whether the cost of care was } \$ 59 \text { or } \\
\$ 75 \text {, and I would like you to tell me whether you would use the option. }\end{array}$} \\
\hline Attributes & Level \\
\hline \multirow[t]{2}{*}{ Symptom scenarios } & $\begin{array}{l}\text { Influenza: You have high fever, dry cough, and a sore throat. Your nose } \\
\text { feels stuffy, you feel extremely tired, and you have muscle pain all } \\
\text { over your body. The symptoms started to develop } 4 \text { days ago, and } \\
\text { seem to have worsened this morning }\end{array}$ \\
\hline & $\begin{array}{l}\text { Urinary tract infection: Since yesterday morning you have been hav- } \\
\text { ing frequent strong urges to urinate that cannot be delayed. Despite } \\
\text { the strong urge, very little urine is released each time, and you feel } \\
\text { a sharp pain or burning sensation in the bladder or urethra area } \\
\text { during urination. This morning you noticed that the urine is tinged } \\
\text { with blood }\end{array}$ \\
\hline \multirow{2}{*}{$\begin{array}{l}\text { Care setting-clinician } \\
\text { combinations }\end{array}$} & Physician at a private practice \\
\hline & $\begin{array}{l}\text { Nurse practitioner at a clinic within a supermarket, discount store, or } \\
\text { chain pharmacy }\end{array}$ \\
\hline \multirow[t]{2}{*}{ Price } & $\$ 59$ \\
\hline & $\$ 75$ \\
\hline \multirow{2}{*}{$\begin{array}{l}\text { Appointment wait } \\
\text { time }\end{array}$} & Same day \\
\hline & \\
\hline
\end{tabular}




\begin{tabular}{|c|c|}
\hline Characteristic & Value \\
\hline Age, mean (SD), years & $49.47(15.38)$ \\
\hline \multicolumn{2}{|l|}{ Race, n (\%) } \\
\hline White & $357(73.6)$ \\
\hline Black & $108(22.3)$ \\
\hline Asian & $3(0.6)$ \\
\hline Hispanic & $6(1.2)$ \\
\hline Multiracial & $11(2.3)$ \\
\hline \multicolumn{2}{|l|}{ Sex, n (\%) } \\
\hline Male & $158(32.0)$ \\
\hline Female & $335(68.0)$ \\
\hline \multicolumn{2}{|l|}{ Education, n (\%) } \\
\hline Less than 12 years & $24(4.9)$ \\
\hline High school diploma/GED & $112(22.9)$ \\
\hline Some college/technical school/no degree & $114(23.3)$ \\
\hline 2-year college & $49(10.0)$ \\
\hline Bachelor's degree & $143(29.2)$ \\
\hline Advanced or professional degree & $47(9.6)$ \\
\hline \multicolumn{2}{|l|}{ Household income, $n(\%)$} \\
\hline Less than $\$ 25,000$ & $50(13.7)$ \\
\hline$\$ 25,000-\$ 49,999$ & $85(23.3)$ \\
\hline$\$ 50,000-\$ 74,999$ & $84(23.0)$ \\
\hline$\$ 75,000$ or more & $146(40.0)$ \\
\hline \multicolumn{2}{|l|}{ Marital status, n (\%) } \\
\hline Married & $309(63.4)$ \\
\hline Divorced & $50(10.3)$ \\
\hline Separated & $6(1.2)$ \\
\hline Widowed & $51(10.5)$ \\
\hline Never married & $71(14.6)$ \\
\hline \multicolumn{2}{|l|}{ Home ownership, n (\%) } \\
\hline Rent & $64(13.4)$ \\
\hline Own & $415(86.6)$ \\
\hline \multicolumn{2}{|l|}{ Lives in an MSA, $n(\%)$} \\
\hline Yes & $383(77.7)$ \\
\hline No & $110(22.3)$ \\
\hline
\end{tabular}

through the Stata statistical software program ${ }^{38}$ after data conversion via the Stat/Transfer program. ${ }^{39}$

\section{RESULTS}

The 493 respondents in this study were predominantly white $(73.6 \%)$ and female $(68 \%)$. Mean age of the respondents was 49.47 years $(\mathrm{SD}=15.38$, median $=50)$; $38.9 \%$ had at least a bachelor's degree, and $4.9 \%$ had less than 12 years of education. Total annual household income was less than $\$ 25,000$ for $13.7 \%$ and $\$ 75,000$ or more for $40.0 \%$ of the respondents. Most respondents $(77.7 \%)$ lived in metropolitan statistical areas, with $49.7 \%$ respondents residing in the Atlanta metropolitan statistical area. Details of the demographic characteristics are displayed in Table 2.

The results of the random-effects logistic regression and the corresponding odds ratios $(\mathrm{OR})$ are displayed in Table 3. The constant term in the regression model estimated the respondents' preference for doing something rather than nothing to address the symptoms. The positive and significant value of the constant term $(5.698 ; 95 \% \mathrm{CI}, 4.726$ to $6.671 ; P<.001)$ indicates that the respondents preferred to seek medical care for both conditions. Respondents were slightly less likely to seek care for UTI than to seek care for influenza $(\beta=-0.149,95 \% \mathrm{CI},-0.259$ to $-0.038, \mathrm{OR}=0.882$; $P=.008)$ and preferred to spend less $(\beta=-0.034,95 \%$ $\mathrm{CI},-0.041$ to $-0.027 ; \mathrm{P}<.001)$. All things equal, the respondents preferred to seek care from a physician at a private office than a nurse practitioner at a retail clinic $(\beta=1.067,95 \% \mathrm{CI}, 0.923$ to $1.212, \mathrm{OR}=2.365$; $P<.001)$ and preferred not to wait 1 day or more for receiving care $(\beta=-2.789,95 \% \mathrm{CI},-2.944$ to -2.635 , $\mathrm{OR}=0.107 ; P<.001)$. There was no statistically significant association between the respondents' decision to

Table 3. Results of the Random-Effects Logistic Regression

\begin{tabular}{|c|c|c|c|c|c|c|}
\hline Variable (Reference Category ${ }^{a}$ ) & $\boldsymbol{\beta}$ & SE & $z$ & $P>|z|$ & $95 \% \mathrm{Cl}$ & Odds Ratio \\
\hline Symptom scenario (urinary tract Infection) & -0.14877 & 0.05635 & -2.64 & .008 & -0.25920 to -0.03833 & 0.882 \\
\hline Appointment wait period (1 day or more) & -2.78922 & 0.07882 & -35.39 & $<.001$ & -2.94371 to -2.63474 & 0.107 \\
\hline Provider care setting (physician at private office) & 1.06723 & 0.07365 & 14.49 & $<.001$ & 0.92288 to 1.21158 & 2.365 \\
\hline Fee & -0.03396 & 0.00353 & -9.62 & $<.001$ & -0.04088 to -0.02705 & - \\
\hline Age & -0.00682 & 0.00372 & -1.83 & .067 & -0.01411 to 0.00047 & - \\
\hline Race (white) & 0.03424 & 0.05786 & 0.59 & .554 & -0.07918 to 0.14765 & NS \\
\hline Sex (male) & -0.04879 & 0.12731 & -0.38 & .702 & -0.29831 to 0.20073 & NS \\
\hline Education (high school or less) & -0.02515 & 0.03632 & -0.69 & .489 & -0.09633 to 0.04603 & NS \\
\hline Income & 0.00597 & 0.02585 & 0.23 & .817 & -0.04469 to 0.05664 & - \\
\hline Constant & 5.69811 & 0.49620 & 11.48 & $<.001$ & 4.72559 to 6.67064 & - \\
\hline
\end{tabular}




\section{Table 4. Calculations of Estimates for Willingness To Pay (WTP)}

\begin{tabular}{|c|c|c|c|}
\hline VariableIAttribute (Choice) & Coefficient $\beta$ & $\begin{array}{c}\text { WTP Calculation } \\
\beta_{\mathrm{j}} \div\left(-\beta_{\text {price }}\right)\end{array}$ & WTP \$ \\
\hline Fee (price) & -0.033965 & - & - \\
\hline $\begin{array}{l}\text { Clinician-care setting (receive care } \\
\text { from physician at private office) }\end{array}$ & 1.067227 & $1.067227 / 0.033965$ & 31.42 \\
\hline $\begin{array}{l}\text { Appointment wait period (wait } \\
1 \text { day or more) }\end{array}$ & -2.789223 & $-2.789223 / 0.033965$ & -82.12 \\
\hline Constant (seek medical care) & 5.698113 & $5.698113 / 0.033965$ & 167.77 \\
\hline
\end{tabular}

These findings will be valuable to both primary care practices and retail clinics in service planning and rate setting as the emerging retail clinic market crystallizes. It cannot be determined from our study, however, whether the relative importance of the time and cost attributes would remain the same when the choice is between seeking care from a nurse practi-

seek care and age, race, sex, education, income, home ownership, marital status, or residence in a metropolitan statistical area.

Willingness-to-pay estimates suggest that, all else being equal, a cost savings of $\$ 31.42$ would be required for the respondents to seek care from a nurse practitioner at a retail clinic. Similarly, a cost savings of $\$ 82.12$ would be required for them to choose to wait 1 day or more. Overall, a savings of $\$ 167.77$ would be required for the respondents not to seek medical care for their symptoms (ie, they would seek care if the cost is less than $\$ 167.77$ ). Table 4 displays the details of willingness-to-pay calculations.

\section{DISCUSSION}

This study provides the first estimates of the consumer utility related to common attributes of the recently emerging retail clinics in the United States. We found that the respondents preferred to seek medical care under both clinical scenarios. Additionally, they preferred to receive care from a physician at a private office, pay less, and receive care on the same day. Given sufficient cost savings, changes in each attribute may also be acceptable to consumers in our sample.

Although these findings are what we expected and consistent with the findings of recent surveys of consumer preferences of retail clinic use, ${ }^{11,40}$ this study is the first in the United States to quantify the relative importance of and the utility associated with the main attributes of retail clinics. Particularly important to note is that the coefficients in the regression model and the corresponding estimates of willingness to pay indicate that the appointment wait period is likely to be the largest determining factor in an individual's choice. Furthermore, the utility (willingness to pay) associated with receiving same-day care is more than twice the utility associated with receiving care from a physician. Primary care physician practices, especially in competitive markets, are therefore likely to derive greater competitive advantage by addressing patient convenience features (such as same-day scheduling, walk-in hours, and extended hours) than by reducing fees. tioner or physician assistant in a physician-led primary care practice and seeking care from a nurse practitioner or physician assistant at a retail clinic.

It is also not possible to predict from our data the impact of retail clinics on overall utilization of outpatient primary care services or on the primary care physician practices. A study in Scotland found a relatively low impact of pharmacy-based minor ailment service on general practitioner workload. ${ }^{41}$ On the other hand, early evidence suggests that some primary care practices in the United States are making changes in their scheduling system to accommodate same-day care, extending their hours, and publicizing fees for routine procedures on their Web sites. ${ }^{42}$ In the same vein, our study does not lend itself to the determination of the impact of retail clinics on access to and overall cost of care. Although proponents see retail clinics as a vehicle for expanding access to care, most retail clinics are currently located in large metropolitan areas and offer a limited set of services. The literature is sparse on what proportion of clients do not have access to care from other sources; however, $27 \%$ to $30 \%$ of the retail clinic users are uninsured. ${ }^{14,40}$ Even though some insurance companies see retail clinics as potential cost-saving vehicles and have started reimbursing for the services, there is concern in some quarters that retail clinics may drive up prescription drug spending. ${ }^{19}$

Another potential limitation of our study is that it was limited to 1 state, although Georgia, particularly the Atlanta metropolitan area, is one of the early markets with a substantial retail clinic presence, and the residents were likely to be more attuned to the characteristics of retail clinics than residents of other areas. The study sample had slightly higher educational attainment and income compared with the state averages and thus may have affected the estimates.

A response (cooperation) rate higher than the rate achieved in this study $(33.1 \%)$ would certainly have yielded more robust estimates of the utilities. As suggested by Kemp and Remington in their review of current challenges for telephone survey research, however, the response rates in random-digit-dial telephone surveys have declined in recent years for various reasons, 
yet telephone surveys continue to play a vital role in public health research and practice. ${ }^{43}$ Our study identified few important factors affecting patient preferences. Further in-depth studies of patient preferences and care-seeking decision making that incorporate additional patient, clinician, and market characteristics and disease scenarios are necessary to refine the estimates of consumer utilities associated with retail clinic use and fully understand the potential impact and long-term future of retail clinics in the US health care system.

\section{To read or post commentaries in response to this article, see it} online at http://www.annfammed.org/cgi/content/full/8/2/117.

Key words: Patient satisfaction; physician office; retail clinic; cost of care; appointments and schedules; patient acceptance of health care

Submitted December 8, 2008; submitted, revised, June 2, 2009; accepted July 27, 2009

Preliminary findings of this study were presented as a poster at the Society for Medical Decision Making 30th Annual Meeting, Philadelphia, Pennsylvania, October 2008.

Disclaimer: The data and tabulation utilized in this document were made available in part by the Survey Research Center of the University of Georgia. Neither the Survey Research Center nor the University of Georgia bears any responsibility for the analyses or interpretation presented here.

\section{References}

1. Burt CW, McCraig LF, Rechtsteiner EA. Ambulatory medical care utilization estimates for 2005. Advance data from vital and health statistics; no. 388. Hyattsville, MD. National Center for Health Statistics. 2007. http://www.cdc.gov/nchs/data/ad/ad388.pdf.

2. Cherry DK, Woodwell DA, Rechtsteiner EA. National ambulatory medical care survey: 2005 summary. Advance data from vital and health statistics; no. 387. Hyattsville, MD. National Center for Health Statistics. 2007. http://www.cdc.gov/nchs/data/ad/ad387.pdf.

3. Murray M, Berwick DM. Advanced access: reducing waiting and delays in primary care. JAMA. 2003;289(8):1035-1040.

4. Robeznieks A. Look who's buying retail: hospitals, health systems, and even physician groups are getting involved in the latest wave of 'convenient-care' clinics. Mod Healthc. 2007;37(46):26-28.

5. Sharkey J. Mini-clinic and pharmacy right there in Terminal C. New York Times. Mar 20, 2007. http://www.nytimes.com/2007/03/20/ business/20clinic.html. Accessed Mar 14, 2008.

6. Sullivan D. Retail health clinics are rolling your way. Fam Pract Manag. 2006;13(5):65-72.

7. Malvey D, Fottler MD. The retail revolution in health care: Who will win and who will lose? Health Care Manage Rev. 2006;31(3):168-178.

8. Merrick A. Walgreen Broadens its health care reach-drugstore chain pitches its network of in-store clinics and work-site centers to employers. Wall Street Journal. 2009 Jan 14:B3.

9. Clinic awareness, use growing. http://supermarketnews.com/news/ clinic_use_0312/index.html. Accessed Mar 14, 2008.

10. University of Michigan CS Mott Children's Hospital. National poll on children's health. More children expected to seek care at retail clinics. 2007 April 18. http://www.med.umich.edu/mott/research/ CBH\%20Poll/NPCH\%20vol\%201\%20issue\%201\%20April\%2022\%2 OFINAL_files/Child\%20Health\%20Poll\%20Report\%20vol1\%20issue 1\%20041807.pdf. Accessed Mar 5, 2008.
11. Many agree on potential benefits of onsite clinics in major retail stores that can provide basic medical services, yet large numbers are also skeptical. Wall Street Journal Online/Harris Interactive health-care poll. 2005 Oct 26. http://www.harrisinteractive.com/ news/newsletters/wsjhealthnews/WSJOnline_HI_Health-CarePoll2005vol4_iss21.pdf. Accessed Mar 17, 2008.

12. Store-based health clinics. Report 7 of the Council on Medical Service (A-06). June 2006. http://www.ama-assn.org/ama1/pub/upload/ mm/372/a-06cmsreport7.pdf. Accessed Mar 17, 2008.

13. Scott MK. Health care in the express lane: the emergence of retail clinics. Prepared for the California Healthcare Foundation. http:// www.chcf.org/topics/view.cfm?itemID =123218. Accessed Mar 17, 2008.

14. Sahoo A. Retail Clinics: A Kalorama Information Market Intelligence Report. New York, NY: Kalorama Information; 2009.

15. Halpren-Ruder D. Capitalism, competition, and commercialism: the healthcare marketplace vs. the medical home. Med Health $R I$. 2005;88(8):289.

16. Berman S. Continuity, the medical home, and retail-based clinics. Pediatrics. 2007;120(5):1123-1125.

17. American Academy of Family Physicians. Desired attributes of retail health clinics. 2007. http://www.aafp.org/online/en/home/policy/ policies/r/retailhealthclinics.html. Accessed Apr 25, 2008.

18. Retail-Based Clinic Policy Work Group, AAP. AAP principles concerning retail-based clinics. Pediatrics. 2006;118(6):2561-2562.

19. Boom in walk-in clinics raises questions about Rx spending, pharmacy records. Drug Benefit News. 2007;8(3):1-3.

20. Bohmer R. The rise of in-store clinics-threat or opportunity? $N$ Engl J Med. 2007;356(8):765-768.

21. Woodburn JD, Smith KL, Nelson GD. Quality of care in the retail health care setting using national clinical guidelines for acute pharyngitis. Am J Med Qual. 2007;22(6):457-462.

22. Nelson R. Retail health clinics on the rise. NPs are finding new job opportunities, but with some old turf issues. Am J Nurs. 2007; 107(7):25-26.

23. FTC staff comment before the Massachusetts Department of Public Health concerning proposed regulation of limited service clinics. http://www.ftc.gov/os/2007/10/v070015massclinic.pdf. Accessed Mar 15, 2008.

24. Massachusetts Department of Public Health. Commonwealth to propose regulations for limited service clinics: rules may promote convenience, greater access to care. 2007. http://www.mass.gov/ ?pageID = pressreleases $\varepsilon$ agld $=$ Eeohhs $2 E$ prModName $=\mathrm{dph}$ pressreleaseEprFile=070717_clinics.xml. Accessed Mar 17, 2008.

25. Probst JC, Greenhouse DL, Selassie AW. Patient and physician satisfaction with an outpatient care visit. J Fam Pract. 1997;45(5): 418-425.

26. Camacho F, Anderson R, Safrit A, Jones AS, Hoffmann P. The relationship between patient's perceived waiting time and office-based practice satisfaction. N C Med J. 2006;67(6):409-413.

27. Anderson RT, Camacho FT, Balkrishnan R. Willing to wait?: the influence of patient wait time on satisfaction with primary care. BMC Health Serv Res. 2007;7:31

28. Kong MC, Camacho FT, Feldman SR, Anderson RT, Balkrishnan R. Correlates of patient satisfaction with physician visit: differences between elderly and non-elderly survey respondents. Health Qual Life Outcomes. 2007;5:62.

29. Jatulis DE, Bundek NI, Legorreta AP. Identifying predictors of satisfaction with access to medical care and quality of care. Am J Med Qual. 1997;12(1):11-18.

30. Meng YY, Jatulis DE, McDonald JP, Legorreta AP. Satisfaction with access to and quality of health care among Medicare enrollees in a health maintenance organization. West J Med. 1997;166(4):242-247. 
31. Porteous T, Ryan M, Bond CM, Hannaford P. Preferences for selfcare or professional advice for minor illness: a discrete choice experiment. Br J Gen Pract. 2006;56(533):911-917.

32. Ryan M, Bate A, Eastmond CJ, Ludbrook A. Use of discrete choice experiments to elicit preferences. Qual Health Care. 2001;10(Suppl 1):i55-i60.

33. Ryan M, Scott D, Reeves C, et al. Eliciting public preferences for health care: a systematic review of techniques. Health Technol Assess Rep. 2001;5(5):1-186

34. Ryan M. Deriving welfare measures in discrete choice experiments: a comment to Lancsar and Savage. Health Econ. 2004;13(9):909912, discussion 919-924.

35. Ryan M, Gerard K, Amaya-Amaya M, eds. Using Discrete Choice Experiments to Value Health and Health Care. The Netherlands: Springer; 2008.

36. Random Digit Telephone Sampling Methodology. Fairfield, CT: Survey Sampling, Inc; 1998.

37. Machlin SR, Carper K. Expenses for office-based physician visits by specialty. Statistical brief no. 166. March, 2007. Rockville, MD. Agency for Healthcare Research and Quality. http://www.meps. ahrq.gov/mepsweb/data_files/publications/st166/stat166.pdf.
38. Stata Statistics/Data Analysis [computer software]. Version 10. College Station, TX: StataCorp; 2007

39. Stat/Transfer File Transfer Utility (for Windows 7) [computer software. Seattle, WA:Circle Systems; 2007.

40. Tu HT, Cohen GR. Checking up on retail-based clinics: is the boom ending? The Commonwealth Fund. December 2008.

41. Schafheutle E, Noyce P, Sheehy C, Jones L. Direct supply of medicines in Scotland: Evaluation of a pilot scheme. Research finding no. 29. Edinburgh: Health and Community Care Research Programme, Scottish Executive Social Research; 2003.

42. Bachman J. What do retail clinics mean for family medicine? Fam Pract Manag. 2006;13(5):19-20

43. Kempf AM, Remington PL. New challenges for telephone survey research in the twenty-first century. Annu Rev Public Health. 2007;28:113-126.

\section{CHANGE-OF-ADDRESS FORM FAMNILY MEDICINE}

Please complete this form and mail to the following address or fax to Annals Circulation at 913-906-6080:

Annals of Family Medicine, Circulation Department, 11400 Tomahawk Creek Pkwy, Leawood, KS 66211-2680

Check if member of sponsoring organization:

$\begin{array}{ll}\square \text { AAFP } & \square \text { ABFM } \square \text { STFM } \square \text { ADFM } \\ \square \text { AFMRD } \square \text { NAPCRG } \square \text { CFPC }\end{array}$

ID number from label on your journal cover

OLD Information (Please print.)

Name

Company (if applicable)

Address (Street plus Apt or Ste)

\begin{tabular}{ll}
\hline City & State \\
\hline Country & Postal Code (9-digit ZIP for US) \\
\hline Telephone & Fax \\
\hline E-Mail &
\end{tabular}

NEW Information (Please print.)

Name

Company (if applicable)

Address (Street plus Apt or Ste)

\begin{tabular}{ll}
\hline City & State \\
\hline Country & Postal Code (9-digit ZIP for US) \\
\hline Telephone & Fax \\
\hline E-Mail & \\
\hline
\end{tabular}

